\title{
1,2,3-Tri(9-anthryl)benzene. Photophysical Properties and Solid State Intermolecular Interactions of Radially Arranged, Congested Aromatic $\pi$-Planes
}

\author{
Tomohiko Nishiuchi, ${ }^{*[a]}$ Hikaru Sotome, ${ }^{*[b]}$ Kazuto Shimizu, ${ }^{[a]}$ Hiroshi Miyasaka, ${ }^{*[b]}$ and Takashi \\ Kubo*[a,c]
}

\author{
[a] Dr. T. Nishiuchi, K. Shimizu, Prof. Dr. T. Kubo \\ Department of Chemistry, Graduate School of Science, Osaka University \\ 1-1 Machikaneyama, Toyonaka, Osaka 560-0043 (Japan) \\ E-mail: nishiuchit13@chem.sci.osaka-u.ac.jp \\ [b] Dr. H. Sotome, Prof. Dr. H. Miyasaka \\ Division of Frontier Materials Science and Center for Advanced Interdisciplinary Research, Graduate School of Engineering Science, Osaka University \\ 1-3 Machikaneyama, Toyonaka, Osaka 560-8531 (Japan) \\ E-mail: sotome@laser.chem.es.osaka-u.ac.jp, miyasaka@chem.es.osaka-u.ac.jp \\ [c] Prof. Dr. T. Kubo \\ Innovative Catalysis Science Division, Institute for Open and Transdisciplinary Research Initiatives, (ICS-OTRI), Osaka University \\ Suita, Osaka 565-0871 (Japan)
}

\begin{abstract}
We report the Negishi coupling based synthesis of $1,2,3$ tri(9-anthryl)benzene derivatives, containing three radially arranged anthracenes in a $\pi$-cluster. In the crystalline state of the unsubstituted derivative, intermolecular $\pi-\pi$ and $\mathrm{CH}-\pi$ interactions between the anthracene units drive the formation of a two-dimensional packing structure. Owing to though-space $\pi$-conjugation between anthracene units, the substances have unique electronic properties. The excited state dynamic behavior occurring between the three radially arranged anthracene moieties, such as exciton localization/delocalization, was elucidated by means of transient absorption measurements and quantum chemical calculations. Interestingly, even though the three anthracenes are closely oriented with a ca. $3.0 \AA$ distances between their C-9 positions, exciton localization on two anthracene units is energetically favorable because of the flexible nature of the radially arranged aromatic rings.
\end{abstract}

\section{Introduction}

$\pi$-Congested aromatic systems, like [n.n]paracyclopahane derivatives $(n=1,2),{ }^{[1,2]}$ which have distances between two $\pi$ planes that are smaller than the sum of van der Waals (vdWs) radii of carbon atoms $(3.40 \AA)$, have unique optoelectronic properties derived from through-space (TS) $\pi$-conjugation. The properties of $\pi$-congested systems are quite different from those of a single aromatic moieties including, for example, they engage in excimer formation even at room temperature and photoreactions occur to form $\mathrm{C}-\mathrm{C}$ bonds between the aromatic planes. ${ }^{[3,4]}$ The interesting properties of $\pi$-congested systems make them fascinating targets not only for fundamental studies aimed at elucidating the nature TS $\pi$-conjugation but also at developing of organic electronic devices. Studies of m-congested systems containing regularly arranged aromatic units are useful for gaining an understanding of the mechanism of exciton delocalization through aromatic units. ${ }^{[5]}$ In particular, because the localization/delocalization behavior of excitons is governed by the arrangement of the aromatic planes, investigations of the dependence of the dynamic behavior of excitons on the arrangement of aromatic rings is an important component of understanding and classifying exciton behavior in complex molecular assemblies.

Recently, we developed a new $\pi$-congested system, called a $\pi$-cluster, ${ }^{[6]}$ which is comprised of anthracene (Ant) units (see 1 and 2 in Figure 1). The strategy employed to construct the system utilizes a rigid benzene scaffold to locate the Ant units within short distances. TS $\pi$-conjugation in the $\pi$-clusters existing between two anthracene units linked at ortho-positions of a benzene ring has been elucidated. The current study was designed to explore TS $\pi$-conjugation in $\pi$-clusters that are comprised of three Ant units. We believed that systems containing Ant trimers, like 1,2,3tri(9-anthryl)-4-t-butylbenzene derivatives 3 that have not yet been synthesized, ${ }^{[7]}$ would be good models to study TS $\pi-$ conjugation and exciton localization/delocalization behavior in radially arranged $\pi$-plane systems. In addition, because of the large size of their aromatic m-planes, Ant units should intermolecularly interact. The role that these interactions play in creating molecular arrangements to construct $1 \mathrm{D}$ or $2 \mathrm{D}$ solid state material would be attractive from the viewpoint of crystal engineering. ${ }^{[8]}$

The results of the study described below show that the parent 1,2,3-tri(9-anthryl)-5-t-butylbenzene (3a) can be prepared using a $\mathrm{Pd}(\mathrm{I})$-catalyzed Negishi coupling process. Moreover, the Ant units in 3a engage in intermolecular $\pi-\pi$ and $\mathrm{CH}-\pi$ interactions in the crystalline state, which lead to formation of a 2D packing structure. Photoirradiation of $3 \mathbf{a}$ generates photoisomer 3a-PI possessing a strained anthracene $4+4$ dimer sub-structure. In contrast, the $n$-butyl substituted analog $3 \mathbf{b}$ does not undergo photoisomerization and its photo-durability enables it to be utilized in femtosecond transient absorption studies to 
elucidate the unique excited state dynamics in trimeric Ant radial m-clusters.

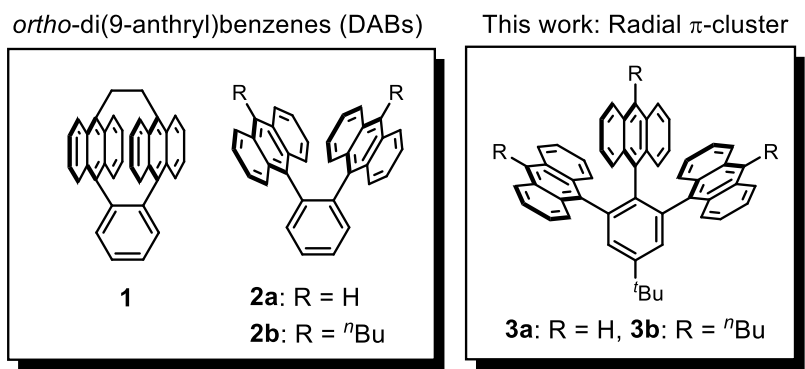

Figure 1. Anthracene-based $\pi$-clusters. Di(9-anthryl)benzenes (1 and 2a-b, left) and tri(9-anthryl)benzenes 3a-b (right, this work)

\section{Results and Discussion}

\section{Synthesis and structure elucidation}

The routes used for synthesis of $\mathbf{3} \mathbf{a}-\mathbf{b}$ are shown in Scheme 1. Although a $S_{N} A r$ reactions between amide anions, such as carbazole anion, and fluorobenzenes are known to be effective in linking large aromatic planar systems to benzene rings ${ }^{[9]}$, related processes employing anthracene or other large hydrocarbon rings have not yet been developed. In contrast, we have previously optimized conditions for $\mathrm{Pd}(\mathrm{I})$ catalyzed Negishi coupling reactions ${ }^{[10]}$ that produce ortho-di(9-anthryl) benzene (DAB) derivatives. ${ }^{[6 \mathrm{~d}]}$ Therefore, these conditions were used to carry out coupling between 1,2,3-triiodo-5-t-butylbenzene $\mathbf{5}$ and zinc reagents $\mathbf{4 b - c}$, prepared from the corresponding bromides by treatment with $n$-BuLi and $\mathrm{ZnCl}_{2}$ at $-78{ }^{\circ} \mathrm{C}$. While this protocol enabled modestly efficient generation of $3 \mathbf{b}-\mathbf{c}$, its use in the direct synthesis of $3 \mathbf{a}$ from the non-substituted bromoanthracene was questionable owing to solubility issues. Therefore, the somewhat sensitive trimethylsilyl (TMS) substituted coupling product 3c was employed to form $3 \mathbf{a}$. It was expected that $\mathbf{3 c}$ would participate in ready desilylation ${ }^{[11]}$ owing to the fact that the C-9 TMS group sterically distorts the Ant plane. ${ }^{[12]}$ Thus, silica gel column purification of $3 \mathrm{c}$ was conducted using $0.5 \%$ triethylamine to prevent extensive decomposition and collect $3 c$ together with its partially desilylation products. Subsequent treatment of the mixture using TBAF afforded $3 a$ in $25 \%$ yield (2 steps).

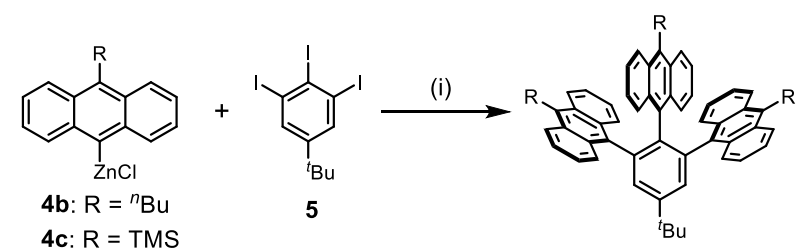

$$
\text { 3b: } \begin{aligned}
& R={ }^{n} \mathrm{Bu}, 30 \% \\
& \text { (ii) } \longrightarrow \text { 3c: } R==\mathrm{TMS} \\
& \text { 3a: } \mathrm{R}=\mathrm{H}, 25 \% \\
& \\
& \text { (2 steps) }
\end{aligned}
$$

Scheme 1. Synthesis of $3 a-b$. (i) $\mathrm{Pd}_{2} \mathrm{I}_{2}\left({ }^{t} \mathrm{Bu} 3{ }_{3} \mathrm{P}\right)_{2}$ (5 mol\% for each reaction site), toluene/THF, $70{ }^{\circ} \mathrm{C}$. (ii) TBAF, THF.

The $\pi$-congestion containing structures of $\mathbf{3 a} \mathbf{a}-\mathbf{b}$ were unambiguously determined by using $\mathrm{X}$-ray crystallographic analysis. The intramolecular shortest $C \cdots C$ distances between neighboring Ant units in these substances are 2.967-3.073 $\AA$ for 3a (Figure 2a-b) and 2.933-3.026 A for 3b (Figure 3a). Three Ant units in $3 a$ adopt perpendicular orientation with respect to the benzene ring whereas those in $\mathbf{3 b}$ are tilted by $67.1-77.3^{\circ}$ toward the benzene ring. Structural optimization of $\mathbf{3 a}$ ', which does not contain the ${ }^{t} \mathrm{Bu}$ group in $\mathbf{3 a}$, by using DFT calculations (M06-2x/6$\left.31 \mathrm{G}^{* *}\right)$, revealed that conformational tilting of the Ant units $\left(C_{2}\right.$ symmetry) occurring in $\mathbf{3 b}$ leads to stabilization by reduction of the repulsive energy between Ant units (Figure S1). In contrast, the perpendicular form ( $C_{2 v}$ symmetry) is an imaginary structure and the energy difference $\Delta G(298.15 \mathrm{~K})$ between the $C_{2}$ and $C_{2 v}$ forms is $6.64 \mathrm{kcal} \mathrm{mol}^{-1}$ (Figure 4).

The reason why Ant units in $\mathbf{3 a}$ adopt a $C_{2 v}$ form in the crystalline state is that they are engaged in multiple $\mathrm{CH}-\pi$ and $\pi-$ $\pi$ intermolecular interactions (Figure $2 \mathrm{c}$ and Figure S2). In the case of the bis-Ant analogue 2a Figure 1), intermolecular Ant interactions do not exist because the core benzene ring occupies the space between two Ant units of neighboring molecules (Figure S3a-b). ${ }^{[6]}$ These types of intermolecular interactions in the crystalline state often take place in multiply arylated molecules. ${ }^{[13]}$ It is noteworthy that triangular type interactions (green square) as well as quadrangular type interactions (yellow square) as part of a herringbone packing pattern also occur between the Ant units in crystalline $3 \mathbf{a}$. The stabilization energies associated with the triangular and quadrangular type interactions were calculated to be $15.6 \mathrm{kcal} \mathrm{mol}^{-1}\left(5.20 \mathrm{kcal} \mathrm{mol}^{-1} /\right.$ Ant unit) and $26.6 \mathrm{kcal} \mathrm{mol}^{-1}$ (6.65 kcal mol-1/Ant unit), respectively (Figure S4). Therefore, the strong $\mathrm{CH}-\pi$ and $\pi-\pi$ interactions compensate for the indigenously unstable nature of the $C_{2 v}$ form and lead to the robust $2 \mathrm{D}$ packing structure of $3 \mathbf{a}$. In contrast, owing to the presence of $n$-butyl groups, the packing structure of $\mathbf{3} \mathbf{b}$ as well as that of $\mathbf{2} \mathbf{b}$ do not have these types of intermolecular interactions between their Ant units (Figure S3c-e).

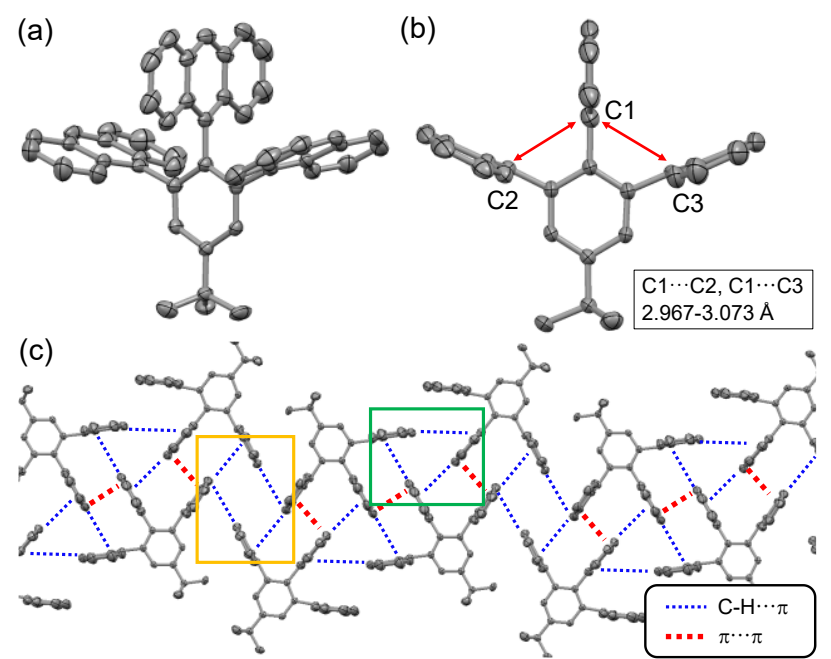

Figure 2. X-ray crystallography derived structure of 3a. (a) Side view. (b) Top view and the shortest $\mathrm{C} \cdots \mathrm{C}$ distances between neighbored Ant units. (c) $2 \mathrm{D}$ alignment of $\mathbf{3 a}$ by intermolecular $\mathrm{CH}-\pi$ and $\pi-\pi$ interactions in the crystal. Protons are omitted for clarity. 
(a)

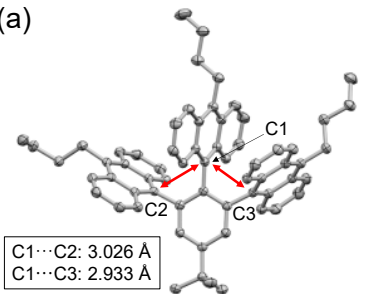

(b)

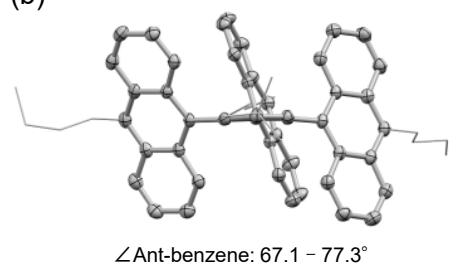

Figure 3. X-ray crystallography derived structure of $\mathbf{3 b}$. (a) Top view and the shortest $\mathrm{C}$. . C distances between neighbored Ant units. (b) Front view and the dihedral angle between Ant units and the benzene ring. Protons are omitted for clarity.

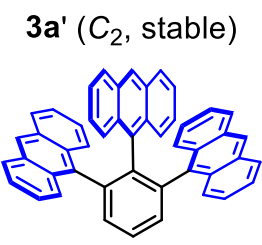

$0.0 \mathrm{kcal} \mathrm{mol}^{-1}$

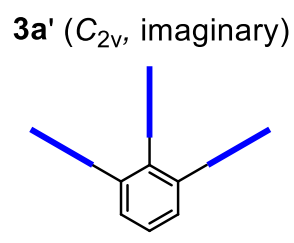

$+6.64 \mathrm{kcal} \mathrm{mol}^{-1}$
Figure 4. Relative energies $(\Delta G)$ between the $C_{2}$ stable form and the $C_{2 v}$ imaginary form of $3 \mathrm{a}^{\prime}$ calculated at the $\mathrm{M} 06-2 \mathrm{x} / 6-31 \mathrm{G}^{* *}$ level of theory.

\section{UV-vis abasorption and emission spectra, and cyclic voltamograms}

UV-vis spectra of $\mathbf{3} \mathbf{a}-\mathbf{b}$ were measured to elucidate the electronic effects of m-clustering of the radially arranged Ant units. A comparison of the spectra of 9-phenylanthracene (PA), 2a and 3a shows that the molar extinction coefficient increases and the longest wavelength maximum slightly red-shifts from 385 to 397 $\mathrm{nm}$ as the number of Ant units increases (Figure 5a). Quantum chemical calculations show that HOMO and LUMO of anthracene are distributed into the HOMO to HOMO-2 and LUMO to LUMO+2 of 3a', respectively, resulting in smaller HOMO-LUMO energy gap for $3 a^{\prime}$ than that for $2 a$ (Figure S5-S6). TD-DFT calculations also show that the absorption maximum of $2 \mathbf{a}(421 \mathrm{~nm})$ is red-shifted in 3a' (439 nm, Table S1-S2), reflecting the effect of accumulating Ant units. Because of the effect of $n$-butyl substitution on the Ant units, $3 \mathrm{~b}$ has a slightly longer absorption maximum $\lambda_{\mathrm{abs}}=410 \mathrm{~nm}$ than does $3 a$ (Figure $5 b$ ). Although three Ant units are accumulated in $\mathbf{3 a - b}$, their $\lambda_{\mathrm{abs}}$ are shorter than that of $\mathbf{1}\left(\lambda_{\mathrm{abs}}=\right.$ $470 \mathrm{~nm}$, Figure S7), ${ }^{[6 \mathrm{~d}]}$ which contains two Ant units. This phenomenon is a consequence of the fact that the face-to-face interaction of two Ant units in 1 located less than $2.9 \AA$ apart is more effective for the HOMO-LUMO energy gap lowering than between the radially arranged of Ant units in $\mathbf{3 a - b}$.
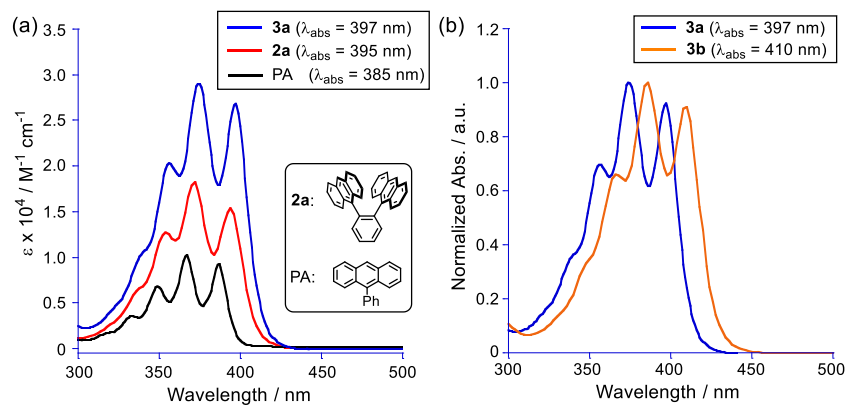

Figure 5. (a) UV-vis spectra of 3a, 2a, and PA in $\mathrm{CH}_{2} \mathrm{Cl}_{2}$. (b) UV-vis spectra of 3a-b in $\mathrm{CH}_{2} \mathrm{Cl}_{2}$. The absorption intensities are normalized. (a)

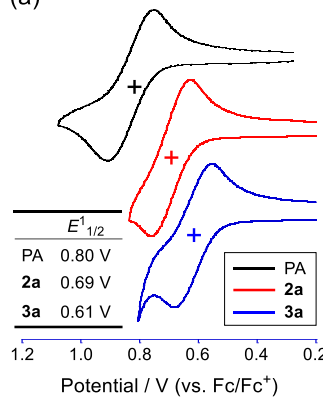

(b)

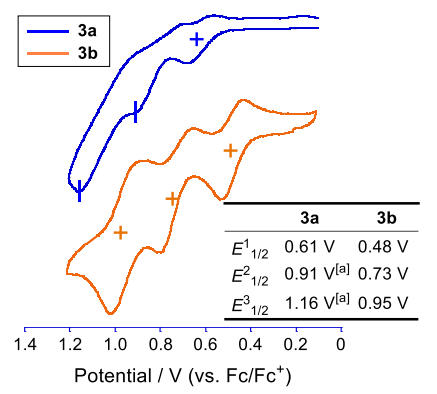

Figure 6. Cyclic voltammograms of (a) first oxidation wave $E_{1 / 2}^{1}$ of $\mathrm{PA}, \mathbf{2} \mathbf{a}$, and 3a. (b) $3 \mathbf{a}$ and $\mathbf{3 b}$. ${ }^{[a]}$ Due to the irreversibilities of the waves, oxidation potentials are given as peak tops $\left(E^{2}\right.$ or $\left.E^{3}\right)$.

The effects of $\pi$-congestion of Ant units are also reflected in redox properties. Analysis of cyclic voltammograms of PA, 2a, and $3 \mathbf{a}$ shows that their respective first oxidation potentials $\left(E_{1 / 2}^{1}\right.$, vs. $\left.\mathrm{Fc} / \mathrm{Fc}^{+}\right)$gradually decrease from +0.80 to +0.69 and to +0.61 $\mathrm{V}$ (Figure 6a). Although the second and third oxidation waves of $\mathbf{3 a}$ are irreversible, those of $n$-butyl substituted analogue $\mathbf{3 b}$ are reversible, indicating that alkyl substitution at $\mathrm{C}-10$ of the Ant unit leads to a stable oxidized state (Figure $6 \mathrm{~b}$ ), as well as reducing the oxidation potential. For example, the first oxidation potentials $E^{1}{ }_{1 / 2}$ of $3 \mathbf{b}$ is $+0.48 \mathrm{~V}$, which is $0.13 \mathrm{~V}$ lower than that of $3 \mathbf{a}$. An identical trend also exists between $\mathbf{2 a}\left(E_{1 / 2}^{1}=+0.69 \mathrm{~V}\right)$ and $\mathbf{2 b}$ $\left(E_{1 / 2}^{1}=+0.56 \mathrm{~V}\right)$ (Figure S8).

The electronic states of $\mathbf{3 a - b}$ have remarkable physical properties. The fluorescence spectrum of $3 \mathbf{b}$ in $\mathrm{CH}_{2} \mathrm{Cl}_{2}$ contains a yellow excimer emission band centered at $520 \mathrm{~nm}$ whereas that of 3a contains a broad emission band at $400-600 \mathrm{~nm}$ (Figure 7a, Table 1). It was found that photoisomerization of $3 \mathbf{a}$ in $\mathrm{CH}_{2} \mathrm{Cl}_{2}$ takes place to form photoisomer 3a-PI during recording the emission spectrum. Thus, the broad spectral band is a result of overlap of the excimer emission of $3 a\left(\lambda_{\mathrm{em}}>500 \mathrm{~nm}\right)$ and Ant monomer emission of 3a-PI ( $\left.\lambda_{\mathrm{em}}=400-450 \mathrm{~nm}\right)$.

$\mathrm{X}$-ray crystallographic analysis of a single crystal of $3 a-\mathrm{PI}$ shows that it has the structure displayed in Figure 8, arising from [4+4] photocycloaddition between the C-9 and C-10 positions of two adjacent Ant moieties. Owing to the presence of the small ring benzocyclobutane moiety, the C9-C9' bond lengths are elongated to $1.678 \AA$ in comparison to those in the non-substituted Ant photodimer $(1.599-1.618 \AA)^{[14]}$, a tendency that is identical to that seen with $2 \mathrm{a}$ and its [4+4] photoisomerization product $2 \mathrm{a}-\mathrm{PI}$. In addition, thermal reversion from $3 a-P I$ to $3 a$ occurs at ca. $150{ }^{\circ} \mathrm{C}$ (Figure S9), a temperature that is the same as that needed to promote thermal reversion from the structurally related $2 \mathrm{a}-\mathrm{PI}$ to 2a. ${ }^{[6 b]}$ The quantum yields $\left(\Phi_{\mathrm{PI}}\right)$ for photoisomerization of $\mathbf{2 a}$ and 3a of $16 \%$ and $8 \%$, respectively (Figure S10), are significantly different. Because of the presence of $n$-butyl substitution on the Ant units in $\mathbf{2} \mathbf{b}$ and $\mathbf{3 b}$ photoisomerization is suppressed and their respective emission quantum yields $\left(\Phi_{\mathrm{Em}}\right)$ are $35 \%$ and $23 \%$, respectively.

The crystalline state emission spectra are different from those for solutions. Specifically, emission bands of $\mathbf{2} \mathbf{a}$ and $\mathbf{2} \mathbf{b}$ in the solid state at 450 and $477 \mathrm{~nm}$, respectively, are significantly blue-shifted compared those in toluene solutions ( $510 \mathrm{~nm}$ ) (Figure 9 , Figure S11-14). This finding indicates that formation of longer wavelength emitting excimers is suppressed in the solid state than it is in the solution state. ${ }^{[15]}$ On the other hand, the emission spectrum of a crystal of $\mathbf{3 a}$ contains only an excimer peak $\lambda_{\mathrm{em}}=$ 
$520 \mathrm{~nm}$, indicating that photoisomerization does not take place in the crystalline state because of strong intermolecular interactions that exist between the Ant units. The emission spectrum of a crystal of $\mathbf{3 b}$ contains peaks not only at $520 \mathrm{~nm}$ but also at 475 $\mathbf{n m}$, which is identical to the wavelength for emission of $\mathbf{2 b}$. Thus, probably because of crystal heterogeneity, two emissive components exist in the crystalline state of $\mathbf{3 b}$, which are associated with the similar arrangement of Ant units present in crystals of $\mathbf{2} \mathbf{b}$ and $\mathbf{3} \mathbf{a}$. The emission lifetime measurements and time-resolved emission spectroscopy studies also indicate that several emissive components exist in the crystal (Figure S15-16 and Table S3).

It is interesting that the relationships between $\Phi_{\mathrm{Em}}$ values of $\mathbf{2 a - b}$ and $\mathbf{3} \mathbf{a}-\mathbf{b}$ in crystalline state are the inverse of those in the solution state. Specifically, the $\Phi_{\mathrm{Em}}$ of $\mathbf{2 a}$ and $\mathbf{3 a}$ in the crystalline state are higher than those in solution whereas the $\Phi_{\mathrm{Em}}$ of $\mathbf{2 b}$ and $\mathbf{3 b}$ in the crystalline state are lower than those in solution. The reason for this lies in the fact that intermolecular embracing of the Ant units in $\mathbf{2 a}$ and $\mathbf{3 a}$ effectively suppresses the non-radiative decay process in the crystalline state.
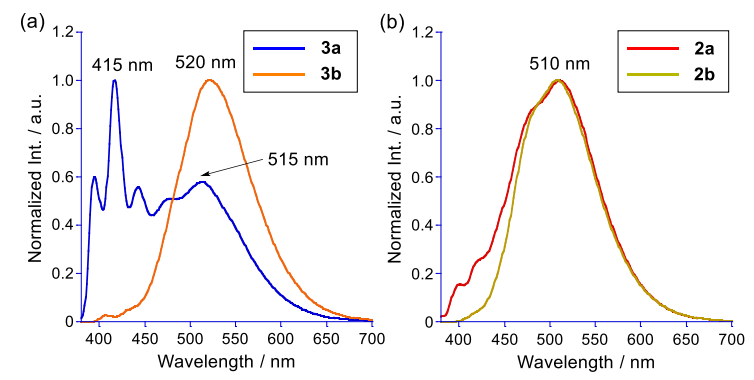

Figure 7. (a) Emission spectra of 3a-b. (b) Emission spectra of 2a-b. The spectra were measured on $\mathrm{CH}_{2} \mathrm{Cl}_{2}$ solutions.

Table 1. Emission wavelength $\lambda_{\mathrm{em}}$, photoisomerization quantum yield $\Phi_{\mathrm{Pl}}$, and emission quantum yield $\Phi_{\mathrm{Em}}$ of $\mathbf{2} \mathbf{a}-\mathbf{b}$ and $\mathbf{3} \mathbf{a}-\mathbf{b}$ in solution and the crystalline state.

\begin{tabular}{|c|c|c|c|c|c|}
\hline & $\lambda_{\mathrm{em}} / \mathrm{nm}^{[\mathrm{a}]}$ & $\Phi_{\mathrm{Pl}}{ }^{[\mathrm{a}]}$ & $\begin{array}{c}\Phi_{\text {Em in }} \\
\text { sol. }^{\text {al] }}\end{array}$ & $\lambda_{\mathrm{em}}$ in cryst. / nm & $\begin{array}{l}\Phi_{\text {Em in }} \\
\text { cryst. }\end{array}$ \\
\hline $2 a$ & 510 & $16 \%$ & $6 \%[c]$ & 450 & $30 \%$ \\
\hline $2 b$ & 510 & $--_{-}^{[b]}$ & $35 \%$ & 477 & $8 \%$ \\
\hline $3 a$ & 415,515 (br.) & $8 \%$ & $16 \%[\mathrm{cc}$ & 520 & $39 \%$ \\
\hline $3 b$ & 520 & $--_{-[b]}$ & $23 \%$ & 475,520 & $12 \%$ \\
\hline
\end{tabular}

[a] Measured on $\mathrm{CH}_{2} \mathrm{Cl}_{2}$ solutions. [b] No photoisomerization occurs with $\mathbf{2} \mathbf{b}$ and 3b. [c] Due to competing photoisomerization, $\Phi_{\mathrm{Em}}$ for $2 \mathrm{a}$ and $3 \mathbf{a}$ change with time and, thus, the determinations of quantitative $\Phi_{\mathrm{Em}}$ for $\mathbf{2 a}$ and $\mathbf{3 a}$ are difficult and the values in the table are first time measurements of $\Phi_{\mathrm{Em}}$ for $\mathbf{2} \mathbf{a}$ and $\mathbf{3} \mathbf{a}$.
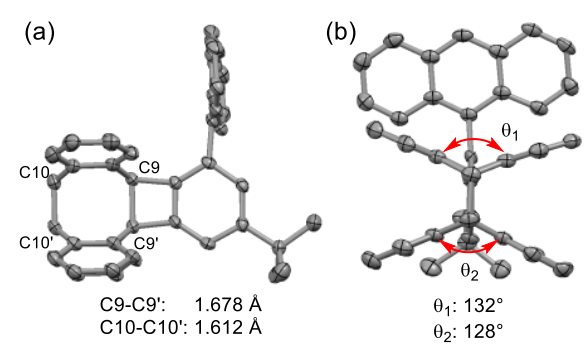

Figure 8. X-ray crystallography of 3a-PI. (a) Side view and C-C distance between C9-C9' and C10-C10'. (b) Front view and bent angles, $\theta_{1}$ and $\theta_{2}$, of Ant photodimer unit. Protons are omitted for clarity.
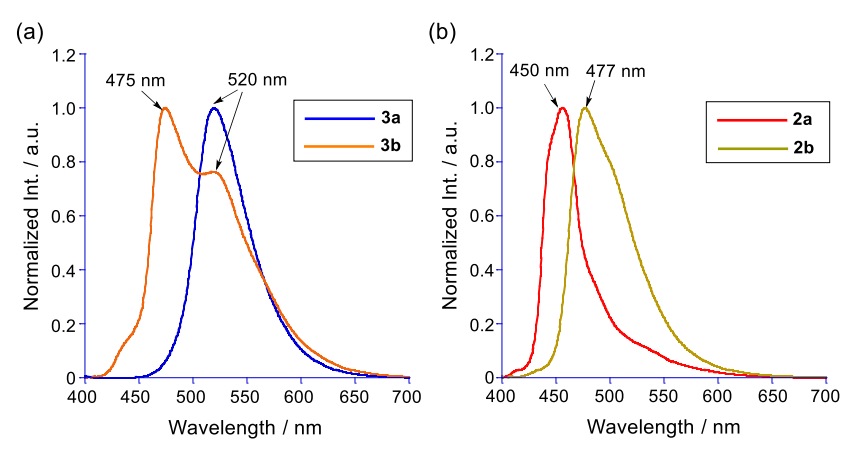

Figure 9. (a) Emission spectra of $3 \mathbf{a}-\mathbf{b}$ in the crystalline state. (b) Emission spectra of $\mathbf{2} \mathbf{a}-\mathbf{b}$ in the crystalline state.

\section{Excited state dynamics}

To elucidate the excited state properties of the tris-Ant derivatives in solution, transient absorption (TA) and emission lifetime measurements were made. The TA spectra of $\mathbf{2 a - b}$ and 3a-b at time zero contain absorption bands in the 500-600 nm range, which are ascribable to the $S_{1}$ state absorption of the Ant monomer unit. ${ }^{[16]}$ The bands are slightly broader than that of anthracene in solution, which is likely a result of structural heterogeneity. The bands at $560 \mathrm{~nm}$ decay within a few picoseconds and other absorption bands concurrently appear at 490 and $880 \mathrm{~nm}$. The two new bands are assigned to the absorption of Ant excimer, ${ }^{[17]}$ which was also observed for the other $\pi$-clusters, 2a and $\mathbf{3 a}$ (Figure 10, 11, S17-19). The timescales $\left(\tau_{\mathrm{ef}}\right)$ for the excimer formation of $\mathbf{2} \mathbf{a}-\mathbf{b}$ and $\mathbf{3} \mathbf{a}-\mathbf{b}$, were quantitatively determined by using global fitting analysis of the corresponding TA data (Table 2). All the time constants are shorter than $10 \mathrm{ps,}$, and extremely faster than those typical for intermolecular excimer formation, where the S1 state forms the excimer with the ground state molecule via the diffusion process in solution. These results clearly show that the arrangement of Ant units at neighboring positions on a benzene ring leads to rapid transition from the monomer excited state to the excimer state. A closer look at the steady-state emission spectra (Figure 7) reveals that the fluorescence band due to the Ant monomer unit (400-450 $\mathrm{nm}$ ) remains present while growth of the dominant excimer emission band in $\mathbf{2} \mathbf{a}-\mathbf{b}$ and $\mathbf{3} \mathbf{a}-\mathbf{b}$ occurs. Taken together, the steady-state and time-resolved spectroscopic data suggest that the Ant excimer is in equilibrium with Ant monomer in the excited states of $\mathbf{2} \mathbf{a}-\mathbf{b}$ and $\mathbf{3} \mathbf{a}-\mathbf{b}$, and the $T_{\mathrm{ef}}$ values are relaxation times for initially produced $\mathrm{S} 1$ monomer to be in monomer-excimer equilibrium.

The $\tau_{\text {ef }}$ values are dependent on the presence of the $n$-butyl group but not on the number of Ant units. For example, $T_{\text {ef }}$ of $2 \mathbf{a}$ and $\mathbf{3 a}$ are 3.4-3.6 times larger than those of $\mathbf{2} \mathbf{b}$ and $\mathbf{3 b}$ probably because $n$-butyl substitution interferes with excimer formation. The excimer emission lifetimes $\tau_{\mathrm{ex}}$ of $\mathbf{2} \mathbf{a}-\mathbf{b}$ and $\mathbf{3} \mathbf{a}-\mathbf{b}$ also exhibit the same dependence on $n$-butyl groups (Figure S20). The results indicate that the exciton in $\mathbf{3} \mathbf{a}-\mathbf{b}$ is mainly localized in two Ant units 

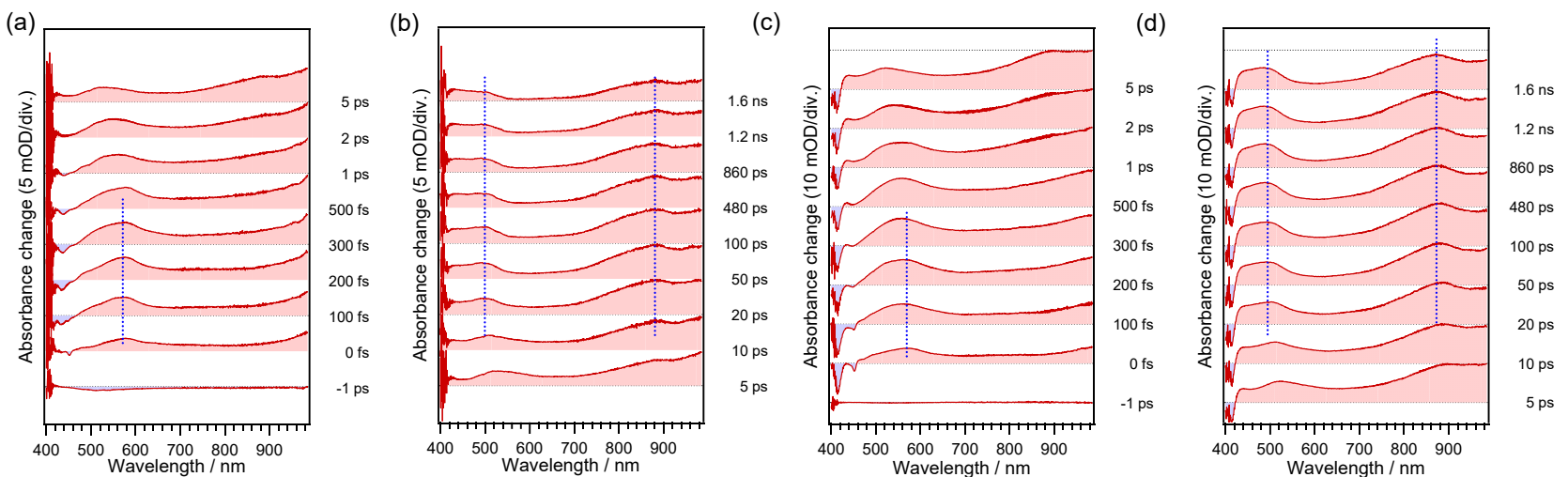

Figure 10. Transient absorption spectra of $\mathbf{2 b}$ and $\mathbf{3 b}$ in toluene solution excited with a femtosecond laser pulse at $400 \mathrm{~nm}$. (a), (b) -1 to 5 ps and $5 \mathrm{ps}$ to 1.6 ns time ranges of $\mathbf{2 b}$. (c), (d) -1 to 5 ps and 5 ps to 1.6 ns time ranges of $\mathbf{3 b}$.

(a)

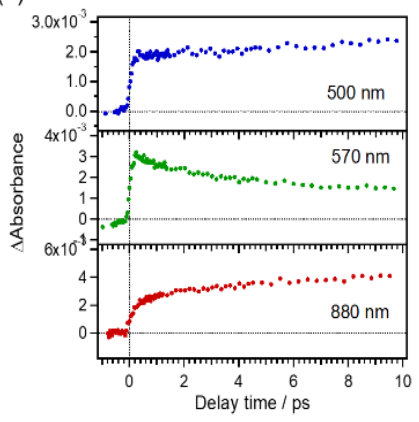

(b)

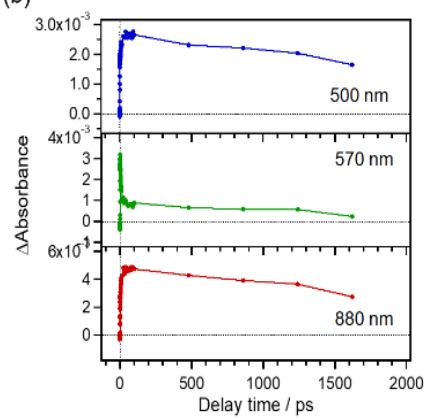

(c)

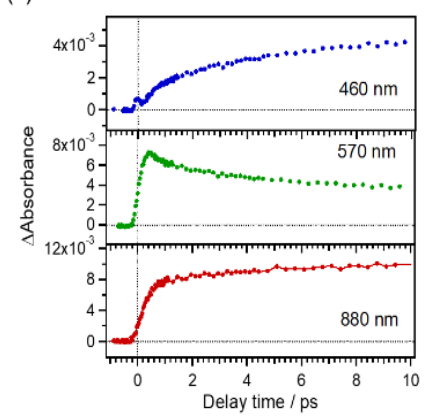

(d)

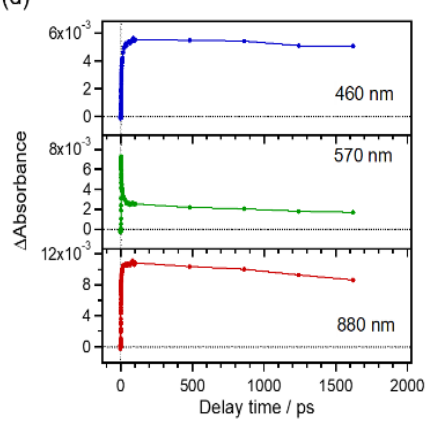

Figure 11. Time profiles of transient absorbance changes of $\mathbf{2 b}$ and $\mathbf{3 b}$ in toluene solution excited at $400 \mathrm{~nm}$. (a), (b) 0 to $10 \mathrm{ps}$ and 0 to $2000 \mathrm{ps}$ time range of 2b. (c), (d) 0 to 10 ps and 0 to 2000 ps time range of $\mathbf{3 b}$.

like that present in $\mathbf{2} \mathbf{a}-\mathbf{b}$ even though three Ant units are in close contact with ca. $3.0 \AA$.

The potential solvatochromic properties of the Ant derivative were evaluated to determine if photoinduced charge separation (CS) occurs in polar solvents. The results show that no significant changes take place in the emission spectra of $\mathbf{2} \mathbf{a}-\mathbf{b}$ and $3 \mathbf{a}-\mathbf{b}$ and that the $\Phi_{\mathrm{Em}}$ values are the same in $\mathrm{CH}_{2} \mathrm{Cl}_{2}$, THF, toluene, and DMF (Figure S21 and Table S4). This result indicated that $\mathbf{2} \mathbf{a}-\mathbf{b}$ and $\mathbf{3} \mathbf{a}-\mathbf{b}$ take no $\mathrm{CS}$ in excited state probably because, unlike the case of $9,9^{\prime}$ - dianthry ${ }^{[18]}$ or ethylene-tethered dianthry ${ }^{[5 a]}$ which is close distance but no significant TS conjugation in ground state, it seems difficult to keep an ion pair state within face-to-face two or three Ant units closely accumulated circumstance.

To gain deeper insight into the photophysical properties, an excited state structural optimization of 3a' was conducted. The results of the calculations $\left(M 06-2 x / 6-31 G^{\star *}\right)$ show that the asymmetric $C_{1}$ form, where two Ant units are close, is more stable by $4.89 \mathrm{kcal} \mathrm{mol}^{-1}\left(\Delta G\right.$ at $298.15 \mathrm{~K}$ ) than the symmetric $C_{2 v}$ form, an imaginary structure where three Ant units are close (Figure 12, S22). Moreover, the LUMO of $3 a^{\prime}$ ' with $C_{2 v}$ symmetry is delocalized over three Ant units whereas the LUMO with $C_{1}$ symmetry is localized on two closely contacted Ant units. These findings indicate that the excimer has the structure of the $C_{1}$ form, which is proper for participation in the photoisomerization reaction. According to the energy difference between two forms, the $C_{2 \mathrm{v}}$ form is likely the transition state for process changing the sites at which the $C_{1}$ form excimer exist. From the calculated value of $\Delta G^{\ddagger}$ $=4.89 \mathrm{kcal} \mathrm{mol}^{-1}$, the timescale of excimer site changing $\left(T_{\mathrm{ESC}}\right)$ in $3 a^{\prime}$ is estimated to be 735 ps $^{[19]}$, which is one order magnitude shorter than the emission lifetime of $\mathbf{3 a} \mathbf{a} \mathbf{b}$. These results indicate that the excited states undergo the change of excimer sites within their nanosecond lifetimes. This consideration is in line with the equilibrium existing between the monomer and excimer as discussed above.

Studies of the excited state dynamics of $\mathbf{2} \mathbf{a}-\mathbf{b}$ and $\mathbf{3} \mathbf{a}-\mathbf{b}$, which have radial arranged $\pi$-systems, have unveiled the unique flexibility of three Ant units and their unusual exciton localization behaior reflected in a tendency to the form an excimer state within two Ant units even though the three Ant units are in close contact in the ground state. A similar phenomenon of exciton localization on two chromophores in three layered $\pi$-system with face-to-face orientation has been reported earlier. ${ }^{[20]}$ Thus, radially arranged $\pi$-systems also have excited state behavior that is similar to that of face-to-face oriented layered $\pi$-systems, which allows to deeper understand the excited state behaviors by unique molecular design with various orientations of aromatic rings.

Table 2. The timescale for excimer formation $T_{\text {ef }}$ and emission lifetime from the excimer $T_{\mathrm{ex}}$ of $\mathbf{2} \mathbf{a}-\mathbf{b}$ and $\mathbf{3} \mathbf{a}-\mathbf{b}$.

\begin{tabular}{ccc}
\hline & $T_{\mathrm{ef}} / \mathrm{ps}^{[\mathrm{a}]}$ & $T_{\mathrm{ex}} / \mathrm{ns}^{[\mathrm{b}]}$ \\
\hline $\mathbf{2 a}$ & 2.10 & 4.79 \\
$\mathbf{2 b}$ & 7.19 & 13.7 \\
$\mathbf{3 a}$ & 1.70 & 7.23 \\
$\mathbf{3 b}$ & 6.21 & 13.6
\end{tabular}

[a] $\tau_{\text {ef }}$ were determined by global analysis of fs-TA. [b] $\tau_{\mathrm{ex}}$ were determined by emission decay analysis. All measurements were conducted in toluene. 


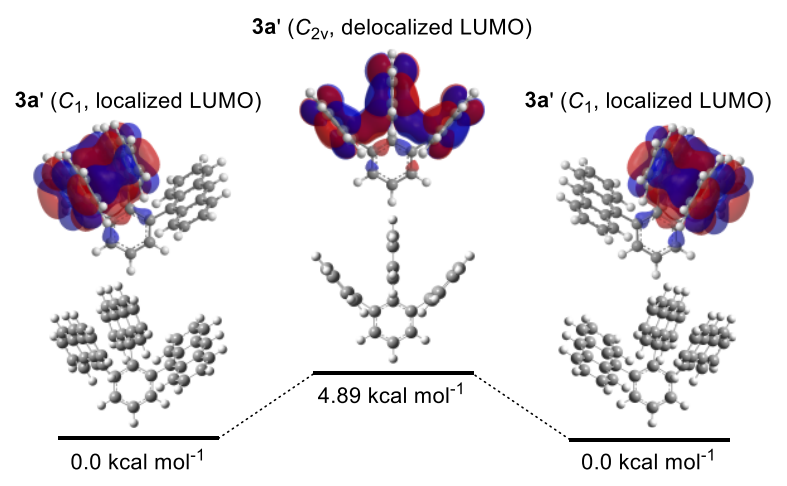

Figure 12. Excited state optimized structures, relative energies ( $\Delta G$ at 298.15 $\mathrm{K})$, and LUMOs of 3a' (M06-2x/6-31G**).

\section{Conclusion}

Substances 3a-b, containing three congested Ant units in radial $\pi$-clusters were synthesized using $P d(I)$-catalyzed Negishi coupling reactions. Analysis of the crystal packing structure of $3 a$ showed that it exists in a high energy $C_{2 v}$ monomer form, in which many intermolecular $\mathrm{CH}-\pi$ and $\pi-\pi$ interactions occur. Thus, substances of this type represent components of a unique strategy to construct highly-ordered 2D molecular structures. TA measurements and quantum chemical calculations showed that the exciton in the excited state of $\mathbf{3 a}$ is not delocalized over three of the radially arranged Ant units but is mainly localized on only two.

An understanding of excited state flexibility and exciton delocalization in $\pi$-congested systems has become important due to recent progress made in several research fields including singlet fission (SF) ${ }^{[21]}$ Based on the current effort, we expect that by suppressing the flexibility of interacting aromatic rings, it might be possible control the nature of an exciton delocalized over three aromatic rings in a manner that would be useful in the SF field.

In a recent theoretical investigation, it was shown that $8 \pi$ electron systems in central six-membered rings between Ant excimer exhibit Baird's aromaticity. ${ }^{[22,23]}$ Interestingly, our finding that localized $C_{1}$ symmetric excimers of $\mathbf{3} \mathbf{a}-\mathbf{b}$ are more stable than delocalized $C_{2 v}$ symmetric excimers is consistent with the concept of Baird's aromaticity. This observation indicates that aromatization stabilization energy is operative in the $C_{1}$ symmetric excimer $\mathbf{3 a - b}$. Therefore, $\pi$-cluster molecules should be attractive targets in studies of aromaticity in ground- and excited states aimed at uncovering relationships between $\pi$-congestion and aromaticity. ${ }^{[24,25]}$ These substances should be useful in the SF research field as well. ${ }^{[26]}$ Furthermore, radial $\pi$-cluster molecules such as a hexa(9-anthryl)benzene and other type cyclic and ladder shape systems will be important targets in investigations to elucidate the detailed nature of $\pi$-clusters.

\section{Acknowledgements}

T. N. would like to thank Prof. Takumi Konno and Prof. Nobuto Yoshinari (Osaka Univ.) for help in measuring emission and excitation spectra, and Prof. Shuichi Suzuki (Osaka Univ.) for help in measuring HR-MS and DSC. ${ }^{1} \mathrm{H}-$ and ${ }^{13} \mathrm{C}-\mathrm{NMR}$, and single crystal X-ray measurements were performed at the Analytical Instrument Facility, Graduate School of Science, Osaka University. Computations were performed using Research Center for Computational Science, Okazaki, Japan. This work was supported by JSPS KAKENHI Grant-in-Aid for Young Scientists (B) JP17K17849 (T. N.), Scientific Research (C) JP20K05475 (T. N.), Transformative Research Areas (A) JP21H05395 (H. S.), and Scientific Research (B) JP21H01888 (H. S.).

Keywords: $\pi$-cluster • anthracene $\mathrm{CH}-\pi$ interaction • photoisomerization $\cdot$ excited state dynamics

[1] a) C. J. Brown, A. C. Farthing, Nature 1949, 164, 915.; b) D. J. Cram, H. Steinberg, J. Am. Chem. Soc. 1951, 73, 5691.; c) J. H. Golden, J. Chem. Soc. 1961, 3741.; d) D. J. Cram, J. M. Cram, Acc. Chem. Res. 1971, 4, 204.; e) T. Umemoto, S. Satani, Y. Sakata, S. Misumi, Tetrahedron Lett 1975, 16, 3159.; f) R. H. Mitchell, R. J. Carruthers, J. C. M. Zwinkels, Tetrahedron Lett. 1976, 17, 2585.; g) H. Irngartinger, R. G. H. Kirrstetter, C. Krieger, H. Rodewald, H. A. Staab, Tetrahedron Lett. 1977, 18, 1425. h) S. Misumi, T. Otsubo, Acc. Chem. Res. 1978, 11, 251.; i) T. Tsuji, M Ohkita, T. Konno, S. Nishida, J. Am. Chem. Soc. 1997, 119, 8425.

[2] F. Diederich in Cyclophanes, The Royal Society of Chemistry: London, 1991.

[3] For typical examples of excimer emission at room temperature, see; a) H. B. -Laurent, A. Castellan, J. -P. Desvergne, R. Lapouyade, Chem. Soc. Rev. 2001, 30, 248.; b) Y. Wu, M. Frasconi, D. M. Gardner, P. R. McGonigal, S. T. Schneebeli, M. R. Wasielewski, J. F. Stoddart, Angew. Chem. Int. Ed. 2014, 53, 9476.

[4] For typical examples of photoisomerization in m-congested system, see; a) T. Toyoda, A. Iwama, Y. Sakata, S. Misumi, Tetrahedron Lett. 1975 , 16, 3203.; b) H. Higuchi, E. Kobayashi, Y. Sakata, S. Misumi, Tetrahedron. 1986, 42, 1731.

[5] a) H. Yao, T. Okada, N. Mataga, J. Phys. Chem. 1989, 93, 7388.; b) H Miyasaka, S. R. Khan, A. Itaya, J. Photochem. Photobiol. C. 2003, 4 195.; c) Z. R. Grabowski, K. Rotkiewicz, Chem. Rev. 2003, 103, 3899.; d) H. S. Cho, H. Rhee, J. K. Song, C. -K. Min, M. Takase, N. Aratani, S. Cho, A. Osuka, T. Joo, D. Kim, J. Am. Chem. Soc. 2003, 125, 5849.; e) I. -W. Hwang, T. Kamada, T. K. Ahn, D. M. Ko, T. Nakamura, A. Tsuda, A. Osuka, D. Kim, J. Am. Chem. Soc. 2004, 126, 16187.; f) Y. Nakamura, I. -W. Hwang, N. Aratani, T. K. Ahn, D. M. Ko, A. Takagi, T. Kawai, T. Matsumoto, D. Kim, A. Osuka, J. Am. Chem. Soc. 2005, 127, 236.; g) R. F. Fink, J. Seibt, V. Engel, M. Renz, M. Kaupp, S. Lochbrunner, H. -M. Zhao, J. Pfister, F. Würthner, B. Engels, J. Am. Chem. Soc. 2008, 130 12858.; h) E. Vauthey, ChemPhysChem. 2012, 13, 2001.; i) Y. Wu, R. M Young, M. Frasconi, S. T. Schneebeli, P. Spenst, D. M. Gardner, K. E. Brown, F. Würthner, J. F. Stoddart, M. R. Wasielewski, J. Am. Chem. Soc. 2015, 137, 13236.

[6] a) F. Schlütter, T. Nishiuchi, V. Enkelmann, K. Müllen, Polym, Chem 2013, 4, 2963.; b) T. Nishiuchi, S. Uno, Y. Hirao, Y. Kubo, J. Org. Chem 2016, 81, 2106.; c) T. Nishiuchi. S. Aibara, T. Kubo, Angew. Chem. Int Ed. 2018, 57, 16516.; d) T. Nishiuchi. K. Kisaka, T. Kubo, Angew. Chem. Int. Ed. 2021, 60, 5400 .

[7] Although Ant oligomers having intramolecular $\pi-\pi$ interaction between Ant units have been synthesized, little of these have distances between Ant units less than 3.3 3.4 $\AA$. Typical Ant-based oligomers, see; a) S. Toyota, M. Goichi, M. Kotani, Angew. Chem. Int. Ed. 2004, 43, 2248.; b) S. Toyota, Pure Appl. Chem. 2012, 84, 917.; c) Y. Morisaki, T. Sawamura, T. Murakami, Y. Chujo, Org. Lett. 2010, 12, 3188.

[8] a) J. Sakamoto, J. v. Heijst, O. Lukin, A. D. Schlüter, Angew. Chem. Int Ed. 2009, 48, 1030.; b) P. Kissel, R. Erni, W. B. Schweizer, M. D. Rossell B. T. King, T. Bauer, S. Götzinger, A. D. Schlüter, J. Sakamoto, Nat. Chem. 2012, 4, 287.; c) R. Bhola, P. Payamyar, D. J. Murray, B. Kumar, A. J. Teator, M. U. Schmidt, S. M. Hammer, A. Saha, J. Sakamoto, A. D Schlüter, B. T. King, J. Am. Chem. Soc. 2013, 135, 14134.; d) D. J. Murray, D. D. Patterson, P. Payamyar, R. Bhola, W. Song, M. Lackinger, A. D. Schlüter, B. T. King, J. Am. Chem. Soc. 2015, 137, 3450.; e) R. Dong, T. Zhang, X. Feng, Chem. Rev. 2018, 118, 6189.

[9] a) H. A. M. Biemans, C. Zhang, P. Smith, H. Kooijman, W. J. J. Smeets A. L. Spek, E. W. Meijer, J. Org. Chem. 1996, 61, 9012.; b) J. J. Piet, H. A. M. Biemans, J. M. Warman, E. W. Meijer, Chem. Phys. Lett. 1998, 289, 13.; c) S. V. Rosokha, I. S. Neretin, D. Sun, J. K. Kochi, J. Am. Chem. 
Soc. 2006, 128, 9394.; d) M. Takase, V. Enkelmann, D. Sebastiani, M. Baumgarten, K. Müllen, Angew. Chem. Int. Ed. 2007, 46, 5524.

[10] a) M. Aufiero, T. Sperger, A. S. -K. Tsang, F. Schoenebeck, Angew. Chem. Int. Ed. 2015, 54, 10322.; b) I. Kalvet, G. Magnin, F. Schoenebeck, Angew. Chem. Int. Ed. 2017, 56, 1581.

[11] H. Cho, R. G. Harvey, J. Org. Chem. 1975, 40, 3097

[12] H. Lehmkuhl, A. Shakoor, K. Mehler, C. Krüger, K. Angermund, Y.-H. Tsay, Chem. Ber. 1985, 118, 4239.

[13] a) I. Dance, M. Scudder, J. Chem. Soc. Chem. Commun. 1995, 1039.; b) I. Dance, M. Scudder, CrystEngComm. 2009, 11, 2233.; c) T. Nishiuchi, H. Sotome, R. Fukuuchi, K. Kamada, H. Miyasaka, T. Kubo, Aggregate. 2021, 2, e126. (DOI: 10.1002/agt2.126.)

[14] a) M. Ehrenberg, Acta Crystallogr. 1966, 20, 177.; b) K. A. Abboud, S. H. Simmonsen, R. M. Roberts, Acta Cryst. C. 1990, 46, 2494.; c) T. Okutsu, K. Isomura, N. Kakinuma, H. Horiuchi, M. Unno, H. Matsumoto, H. Hiratsuka, Crystal Growth \& Design, 2005, 5, 461.

[15] Excimer formation with greater aromatic-aromatic interaction reflects longer wavelength emission, see; T. Hayashi, N. Mataga, Y. Sakata, S. Misumi, M. Morita, J. Tanaka, J. Am. Chem. Soc. 1976, 98, 5910.

[16] C. R. Goldschmidt, M. Ottolenghi, Chem. Phys. Lett. 1970, 4, 570

[17] a) S. Hashimoto, N. Fukazawa, H. Fukumura, H. Masuhara, Chem. Phys. Lett. 1994, 219, 445.; b) R. Katoh, E. Katoh, N. Nakashima, M. Yuuki, M. Kotani, J. Phys. Chem. A, 1997, 101, 7725.

[18] F. Schneider, E. Lippert, Ber. Bunsenges. Phys. Chem. 1968, 72, 1155.

[19] The timescale of the excimer site change, $T_{E S C}$, was calculated by using the Eyling equation $1 / \tau_{\mathrm{ESC}}=k_{\mathrm{ESC}}=\left(k_{\mathrm{B}} \mathrm{T} / h\right) \exp \left(-\Delta G^{\ddagger} / R T\right)$, where $k_{\mathrm{B}}$ is Boltzmann constant, $T$ is temperature, $h$ is Plank constant, $\Delta G^{\ddagger}$ is activation barrier for the excimer site changing, and $R$ is gas constant.

[20] J. M. Giaimo, J. V. Lockard, L. E. Sinks, A. M. Scott, T. M. Wilson, M. R. Wasielewski, J. Phys. Chem. A. 2008, 112, 2322.

[21] a) S. Singh, W. J. Jones, W. Siebrand, B. P. Stoicheff, W. G. Schneider, J. Chem. Soc. 1965, 42, 330.; b) C. E. Swenberg, W. T. Stacy, Chem. Phys. Lett. 1968, 2, 327.; c) M. B. Smith, J. Michl, Chem. Rev. 2010, 110 6891.; d) K. Miyata, F. S. C-. Burton, F. L. Geyer, X.-Y. Zhu, Chem. Rev. 2019, 119, 4261.; e) T. Ullrich, D. Munz, D. M. Guldi, Chem. Soc. Rev. 2021, 50, 3485.

[22] For the concept of Baird's aromaticity, see; a) N. C. Baird, J. Am. Chem. Soc. 1972, 94, 4941.; b) M. Rosenberg, C. Dahlstrand, K. Kliså, H. Ottoson, Chem. Rev. 2014, 114, 5379.

[23] V. Vijay, M. Madhu, R. Ramakrishnan, A. Benny, M. Hariharan, ChemCommun, 2020, 56, 225.

[24] In 2005, R. Herges et. al., proposed that [2.2]paracyclophane, which is a typical $\pi$-congested molecule, possesses an antiaromaticity, confirmed by the existence of a paratropic ring current at the space between two benzene rings in ground state, from ACID calculations. See the chapter 4.3 in this review; D. Geuenich, K. Hess, F. Koehler, R. Herges, Chem. Rev. 2005, 105, 3758.

[25] For the concept of stacked aromaticity by congesting two antiaromatic rings, see; a) M. C. Böhm, P. Bickert, K. Hafner, V. Boekelheide, Proc. Natl. Acad. Sci. 1984, 81, 2589.; b) C. Corminboeuf, P. v. R. Schleyer, P Warner, Org. Lett. 2007, 9, 3263.; c) D. E. Bean, P. W. Fowler, Org. Lett 2008, 10, 5573.; d) J-i, Aihara, J. Phys. Chem. A. 2009, 113, 7945.; e) R. Nozawa, H. Tanaka, W.-Y. Cha, Y. Hong, I. Hisaki, S. Shimizu, J.-Y. Shin, T. Kowalczyk, S. Irle, D. Kim, H. Shinokubo, Nat. Commun, 2016 7, 13620.; f) R. Nozawa, J. Kim, J. Oh, A. Lamping, Y. Wang, S. Shimizu, I. Hisaki, T. Kowalczyk, H. Fliegl, D. Kim, H. Shinokubo, Nat. Commun, 2019, 10, 3576.

[26] Recently, the idea of using ground- and excited state aromaticity for the molecular design of SF chromophores has been investigated, see; a) $\mathrm{K}$. J. Fallon, P. Budden, E. Salvadori, A. M. Ganose, C. N. Savory, L. Eyre, S. Dowland, Q. Ai, S. Goodlett, C. Risko, D. O. Scanlon, C. W. M. Kay, A. Rao, R. H. Friend, A. J. Musser, H. Bronstein, J. Am. Chem. Soc. 2019 141, 13867.; b) J. L. Ryerson, A. Zaykov, L. E. A. Suarez, R. W. A Havenith, B. R. Stepp, P. I. Dron, J. Kaleta, A. Akdag, S. J. Teat, T. F. Magnera, J. R. Miller, Z. Havlas, R. Broer, S. Faraji, J. Michl, J. C Johnson, J. Chem. Phys. 2019, 151, 184903.; c) O. E. Bakouri, J. R. Smith, H. Ottosson, J. Am. Chem. Soc. 2020, 142, 5602. 